Rybaczewska, M., Kłopocka, A. M., Kuszewski, T., \& Sułkowski, L. (2021).

Consumers' response to pandemic threat: Purchase behaviour in convenience

stores. Evidence from British panel data. Journal of International Studies, 14(4), 251 -

269. doi:10.14254/2071-8330.2021/14-4/17

\title{
Consumers' response to pandemic threat: Purchase behaviour in convenience stores. Evidence from British panel data
}

\author{
Maria Rybaczewska \\ Stirling Management School, University of Stirling, \\ United Kingdom \\ maria.rybaczenska@stir.ac.uk. \\ Faculty of Marketing, University of Social Sciences in Lódx, \\ Poland \\ ORCID 0000-0002-0098-1991
}

\section{Aneta Maria Kłopocka}

Department of Management and Finance, University of Economics

and Human Sciences in Warsaw,

Poland

a.klopocka@vinja.pl

ORCID 0000-0002-7940-5910

\section{Tomasz Kuszewski}

Department of Management and Finance, University of Economics

and Human Sciences in Warsaw,

Poland

t.kuszewski@vizja.pl

ORCID 0000-0001-7334-3926

\section{Lukasz Sułkowski}

Faculty of Management and Social Communication, Jagiellonian

University,

Poland

Imkasz.sulkowski@uj.edu.pl

ORCID 0000-0002-1248-2743

Abstract. 1) Background: Consumers' response to threat is an important topic and needs further exploration, especially in times of Covid-19 pandemic. This paper contributes towards widening its understanding from the perspective of consumers' purchase behaviour in the context of convenience stores. It adds to the debate on the influence of the Covid-19 threat and all unprecedented pandemic circumstances (exogenous and endogenous impacts) on consumers' purchase routines and habits. 2) Methods: This study analyses a unique dataset of

Received: January, 2021 1st Revision: October, 2021

Accepted: December, 2021 
transactional data (783,502 observations) drawn from 1,291 convenience stores located in the United Kingdom (thanks to The Retail Data Partnership Ltd). The captured period includes 36 months (from January 2018 till December 2020). This panel data study concentrates on the particular aspects of purchase behaviour (one item transactions, average spend per transaction) in the prepandemic and pandemic period. 3) Results: This investigation reveals that the share of one item transactions fundamentally decreased in the analysed pandemic period (especially in April 2020) both in the overall number and value of transactions. The average transaction (basket) value increased in that period. Further analysis concerning the stores' location, affiliation and size adds depth to our contribution. 4) Conclusions: Our findings show the meaning of convenience sector in times of threat. We demonstrate specific aspects of the claim that purchase behaviour habits and patterns have significantly changed in the era of Covid-19 pandemic. Understanding this change underpins the long-term process of knowledge building in the field of consumers' purchase behaviour. It also makes business practitioners, policymakers and consumers more proactive than reactive in the case of future.

Keywords: consumers' purchase behaviour, Covid-19 pandemic, convenience store sector, the United Kingdom, panel data.

JEL Classification: D12, D91, M31, M30

\section{INTRODUCTION}

Myriad various threats defining our times show that such destabilisation and the lack of security disrupt and alter consumers' lives (Bardhi \& Eckhardt, 2017; Fetzer et al., 2020; Giddens, 1991; Hesham, Riadh, \& Sihem, 2021). Whilst the threats are unavoidable elements of the reality, Covid-19 pandemic brought many unprecedented circumstances that need far more exploration at an individual, national and international/global level. This paper addresses this gap in knowledge by widening the understanding of the consumers' responses to threats. We build our study on the conceptual framework introduced by Campbell et al. (2020) and concentrate on the consumers' behaviour shifts.

Consumers' purchase behaviour has been treated by theorists and practitioners as one of the most significant and consequential topics for decades (e.g. Baumeister et al., 2017, Kłopocka, 2017, Kotler \& Armstrong, 2010, Nicosia, 1966, Rybaczewska \& Sparks, 2019). Therefore our goal is to contribute to the ongoing debate about various aspects of consumers' purchase behaviour (e.g. Branco, Sun, and Villas-Boas 2016, Davvetas \& Diamantopoulos, 2017, Diallo, 2012; Orji, 2013; Prakash et al., 2019, Rybaczewska \& Sułkowski, 2020) by contextualising it within the framework for understanding consumers' responses to threats (Campbell et al., 2020). We address this gap in knowledge and aim to explore consumers' purchase habits and routines being among other aspects of consumer "adaptive" response to turbulent and unprecedented Covid-19 circumstances (lockdowns, regulations, restrictions etc.). We expand the discourse concerning the consumers' purchase behaviour in retail in the era of Covid-19 pandemic (e.g. Keane \& Neal, 2021; Kirk \& Rifkin, 2020; Prentice, Chen, \& Stantic, 2020; PWC, 2020; Sparks, 2020; Sparks, 2021) by focusing on the convenience store sector that is strategically very important for both economy, in the macro scale, and the survival of individual households, in the micro scale (e.g. ACS, 2020). 
To achieve the research goals this paper includes six sections. This introduction is followed by the conceptual framework discussing the outline we build our study on. The third element of this paper describes the methodology of our investigation. Methodology and Data section shows the dataset we analyse and its origin. Discussion and Conclusions contextualised within the goals of our study and the addressed circumstances are preceded by Findings section presenting the results of our investigation. Limitations of this study and further research directions are discussed in the final section of this paper, followed only by references and acknowledgements.

\section{A CONCEPTUAL FRAMEWORK}

\subsection{Covid-19 pandemic as a threat that consumers face}

Natural disasters, global migration, misinformation and dynamic institutional, technological and economic alterations are threats that every consumer needs to be aware of. These threats are initially external but the consequences and impacts on consumers' well-being are both exogenous and endogenous. Pandemic can be placed among such characterised threats.

Covid-19 brought many unexpected and unprecedented regulations and circumstances that the societies and economies need to face. Some consequences are already known (October 2021), some are still impossible to be identified and predicted. Literature supports the opinion that they are all important to analyse and can serve as a precious lesson for the future (Campbell et al., 2020; Hesham et al., 2021). The situation is extremely complex and dynamic in various fields, e.g. health (Brose et al. 2020; Zvolensky et al. 2020), economics (Bonaparte 2020; Fetzer et al., 2020), safety (Tahir \& Batool, 2020; Urch \& George, 2020), retail (Roggeveen \& Sethuraman, 2020) and consumer behaviour (Kirk and Rifkin 2020; Sheth 2020). Uncertainty becomes the most prevalent characteristic of the current world in all dimensions (from the global economy to every single household and/or individual). The overall trends, including globalisation, are not as definite as before and 'new normal' is still very difficult to define (Leiva-Leon, Pérez-Quirós, \& Rots, 2020; Sułkowski, 2020). In the log-term perspective all these unquestionably influence the ontological security understood as a degree to which consumers feel their world, and role within it, is secure and predictable (Campbell et al., 2020; Cannon et al., 2019; Laing, 2010). This term was introduced by Robert Laing (Laing, 2010) and further investigated by researchers (Banham, 2020; Bondi, 2014) addressing the ontological security and insecurity differentiation. They conclude that the ontological insecurity is not simply the lack of security but there is a continuum between them (Campbell et al. 2020). This makes the pandemic unstable circumstances even more related to the ontological security issues (especially in the post-Brexit reality in the United Kingdom).

\subsection{Consumers' "adaptive" responses to pandemic threat - purchase behaviour}

This research builds upon the framework of consumer responses to threats introduced by Campbell et al. (2020). We follow the conceptual model explaining the relationships between such elements like: Actual/Potential Threat, Disruption, Ontological Security, Consumer "Adaptive" Responses and Market/Institution "Adaptive" Responses and add more details in the field of Consumer "Adaptive" Responses (Figure 1).

The extent of threat in the case of Covid-19 pandemic increased significantly due to multiple threats that co-occurred. Health threat widened very dynamically into economic, informational and social threats. Therefore, disruptions in many fields, including everyday functioning, are very easy to notice. The lack of predictable and expected course of life raises uncertainty and overall scarcity of the ontological security 
(Cannon et al. 2019). According to the literature such feelings of insecurity and uncertainty make consumers respond in various affective, cognitive and behavioural way (Campbell et al. 2020).

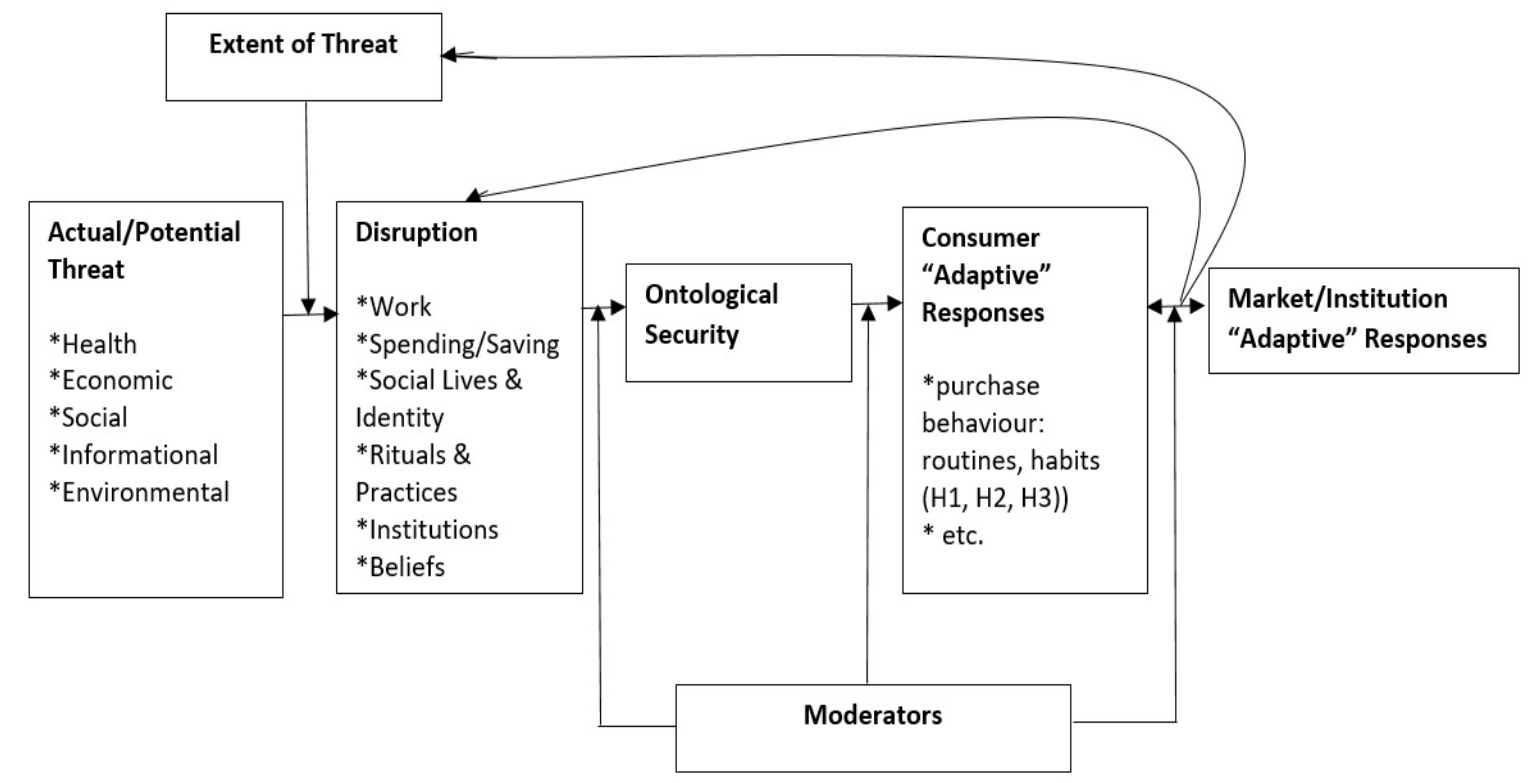

Figure 1. A conceptual framework of purchase behaviour placed among consumer "adaptive" responses to pandemic threat

Source: Authors' own upon Campbell et al. (2020), p. 313.

Therefore the main interests of this study refer to the consumer "adaptive" responses to the pandemic threat. Due to the emotional nature of uncertainty and insecurity emotional response is a key in this context (Banham 2020). Literature suggests the whole variety of emotional reactions (stress, sadness, anger, anxiety etc.), including avoidance of crowds, increased indulgence, increased purchase and consumption, materialism, feelings of loss control etc. (e.g. Ferraro, Shiv, and Bettman 2005; Mandel and Smeesters 2008; Rindfleisch, Burroughs, and Wong 2009). Simultaneously Covid-19 has already brought the issues around loneliness (Miller 2020; Palgi et al. 2020), overall mental health (Brose et al. 2020) etc. More importantly for this study literature consistently claims that due to experienced threats (and ontological insecurity as a result) consumers often change their purchase habits and routines (Kirk and Rifkin 2020; Phipps and Ozanne 2017; Sheth 2020). Undoubtedly Covid-19 with its all short- and long-term consequences has already highly influenced the environment of the purchase decisions made by consumers (both endogenous and exogenous factors) and this is still ongoing impact (Fetzer et al. 2020; Sułkowski 2020; Zvolensky et al. 2020).

Following the goal of this study to extend exploration of the interdisciplinary field of consumers' purchase behaviour we address the gap in knowledge concerning the consumers' "adaptive" response to pandemic threat in the field of purchase routines and habits. Therefore we formulate hypotheses addressing specific aspects of consumers' emotional response to threat (e.g. avoiding crowds, following the governmental guidance and 'stay at home' recommendations, avoid panic buying) influencing the overall purchase habits and routines in the times of Covid-19 pandemic threat (Campbell et al. 2020; Grashuis, Skevas, and Segovia 2020; Hesham et al. 2021; Ortega-Vivanco 2020; Szymkowiak et al. 2021). The isolation and loneliness issues connected with the Covid-19 and lockdowns reality (Miller 2020; Palgi et al. 2020; 
Zvolensky et al. 2020) add another dimension to overall purchase behaviour, including online transactions. They became typical even for unexpected areas of sales enforcing companies to develop their network of relationship with customers (Nurliza \& Oktoriana, 2021). Even though the trend of increasing share of Internet sale in the total retail sale has been observed in many countries for relatively long period, Covid-19 pandemic in 2020 brought the unprecedented growth of online shopping in the UK (ONS 2021). This leads to various reflections not only on consumers' purchase habits and patterns but also the role, presence and future of stationery shops and the whole convenience sector.

Therefore we concentrate on consumers' purchase habits in the context of the convenience store sector providing everyday products being more important in the times of threat than ever (such stores were open in the UK during all analysed lockdowns). These stores were reliable source of essential products when panic buying and disrupted supply chains (due to Covid-19 and Brexit in the UK) significantly influenced/limited the product availability (Islam et al., 2021; Keane \& Neal, 2021), especially in some particular categories (Kirk \& Rifkin, 2020). Convenience stores are also perceived as a focal point for the local community (Rybaczewska \& Sparks, 2020) which is priceless in times of trouble when the relationships within the neighbourhoods play fundamental role, especially in the case of the most vulnerable individuals. Convenience stores are connected with the personal interactions, often close bonds full of trust, incredibly vital for those who suffer from loneliness etc. All these needs cannot be fulfilled with the anonymous retail (e.g. online, megastores). What is more, the convenience store sector is often highly connected with the sustainability and well-being of local communities and places. This sector is often linked with the overall place resilience and such concepts like local and circular economy, 20 minute neighbourhood etc. (A New Future for Scotland's Town Centres, 2020). Additionally, the Scottish Local Shop Report 2021 by the Association of Convenience Stores and the Scottish Grocers Federation (ACS and SGF 2021) revealed that 47,079 stores in the UK convenience sector currently employ around 392,000 people, generating sales of $£ 43$.2bn over the last year. All these factors make the convenience store sector exceptionally important in times of uncertainty and threats, therefore worth researching especially in the context of such circumstances.

Do the customers follow the lockdown restrictions (including social distancing) and avoid crowd in the supermarkets/megastores by doing their everyday shopping online or by shopping more in convenience stores, very often run by the independent/local retailers? If the convenience store sector is relatively resilient and overall turnover did not meaningfully decreased last year (Rybaczewska et al., 2021; ACS, 2020, ACS and SGF, 2021) Association of Convenience Stores 2020, Association of Convenience Stores and The Scottish Grocers Federation 2021) what happened with the consumers' purchase routines and habits?

Taking into consideration the discussed issues connected with the ontological security and insecurity (loneliness, everyday needs, governmental recommendations, restrictions etc.), we build upon work of such authors like Islam et al. (2021); Keane and Neal (2021), Ortega-Vivanco (2020) and we concentrate on specific indicators of purchase routines and habits: percentage share of one item transactions (single basket) in the overall number of transactions, the share of value of one item transactions (single basket) in the overall turnover and the amount of money spent during one transaction (average basket). Consumers following the governmental 'stay at home' recommendations might buy only one item during their visit in store not as often as before. Another case would be to use this one item shopping opportunity to get any kind of personal interaction while suffering from loneliness resulting from lockdown (Miller, 2020; Palgi et al., 2020). At the same time, though, the same consumers may use Internet to do their shopping and buy only one item that they forget to buy online/need to be fresh. Acknowledging all these possibilities we hypothesise that overall share of single basket transactions would decrease. This leads us to the question concerning the money spent on such single basket purchases, are these items bought as a single basket transaction cheaper/more expensive than before Covid-19? We hypothesise that the share of such transactions in the overall turnover decreased. This raises questions though about the average basket spend. 
The convenience store sector may be perceived as resilient during Covid-19 (Rybaczewska et al., 2021) thanks to increased number of customers or higher average basket spend. To verify all these we formulate two hypotheses:

H1: Percentage share of single basket transactions decreased in the analysed time of Covid-19 pandemic threat:

H1.1. in the total number of transactions.

H1.2. in the overall turnover.

H2: The average basket spend increased in the analysed time of Covid-19 pandemic threat.

Loneliness, social distance and avoiding crowd issues add another dimensions to our analysis i.e. store location - ONS regions (addressing the population density in the neighbourhood) and size of the store. All these are important from the perspective of the subjective and emotional consumers' perception of the purchase decision circumstances, especially in the context of ontological security and insecurity.

In the same context brand trust, connected with the store affiliation here, cannot be omitted in the analysis. Trust, priceless in times of uncertainty, is one of the major features for the customer and company relationships (Lien et al., 2015), it belongs to important constituents of subjective perception of quality of life (Tvaronavičienè et al., 2021). It also refers to the positive belief of the customer on perceived product, services and the brand (Park \& Kim 2016; Modliński \& Gladden, 2021), referring to customer loyalty which is always in focus in customers relationship management (Shava, 2021). Acknowledging that the trusted brands are purchased more willingly since the perceived risk for choosing or purchasing the particular brand is lower (Atulkar, 2020) we test the affiliated and unaffiliated stores (recognising the unaffiliated stores as possibly very well-perceived and well-known by their customers, often in the long-term perspective).

\section{METHODOLOGY AND DATA}

We use the unique dataset of the real life transactional data, drawn from a representative sample of 1,291 convenience stores (affiliated and unaffiliated) located in the United Kingdom (thanks to The Retail Data Partnership Ltd (TRDP)). TRDP has worked with retailers for more than 20 years to help them improve their business by developing ShopMate, the convenience sector's most dependable EPoS system. Table 1 shows the structure of the analysed convenience stores. They are located around the whole UK (majority in England (76.2\%) and in most cases they are affiliated (74.3\%). In terms of ONS regions the vast majority of stores are located in urban larger area $(68.6 \%)$ and the most seldom location is described as Town and Fringe Sparse (1.5\%). The most common (83\%) size of the store is described as medium (average turnover in this store is more than 0.5 and less than 1.5 of average turnover for all analysed stores and the number of tills equals 1 or 2 ).

Using TRDP data we study the period of 36 months, starting from January 2018 till December 2020. In early 2020 the Covid-19 struck with unimaginable consequences, which are still playing out. In January and February 2020 the pandemic was acknowledged but not that spread yet and the restrictions in the United Kingdom were not that severe. Following the governmental guidance the first lockdown was fully introduced and implemented in the UK on the 16th March 2020 (in the retail context it was not as impactful immediately in March as it was the following month i.e. April 2020). Afterwards, as in many other countries, the regulations were dependent on the health safety requirements i.e. some restrictions were constantly in place since March 2020 till now (October 2021) but the majority evolved just as the pandemic progressed/regressed. 
Characteristics of the analysed convenience stores

\begin{tabular}{|l|l|c|}
\hline \multirow{2}{*}{ Description } & \multicolumn{1}{c|}{$\begin{array}{c}\text { Percentage share in overall } \\
\text { number (1291) }\end{array}$} \\
\hline Location & England & $76.2 \%$ \\
\cline { 2 - 3 } & Scotland & $9.5 \%$ \\
\cline { 2 - 3 } & Wales & $13.6 \%$ \\
\cline { 2 - 3 } & Nothern Ireland & $0.7 \%$ \\
\hline Affiliation & Affiliated & $74.3 \%$ \\
\hline \multirow{5}{*}{ Office for National Statistics (ONS) regions } & $25.7 \%$ \\
\hline \multirow{5}{*}{ Unaffiliated } & $13.7 \%$ \\
\hline & Town and Fringe & $1.5 \%$ \\
\cline { 2 - 3 } & Town and Fringe Sparse & $68.5 \%$ \\
\cline { 2 - 3 } & Urban Larger & $6.3 \%$ \\
\cline { 2 - 3 } & Urban Smaller & $10.0 \%$ \\
\cline { 2 - 3 } & Villages and Remote Rural & $11.4 \%$ \\
\hline Store Size & Large & $82.9 \%$ \\
\hline \multirow{3}{*}{ Medium } & $5.7 \%$ \\
\cline { 2 - 3 } & Small & \\
\cline { 2 - 3 } & & \\
\cline { 2 - 3 } & & \\
\hline
\end{tabular}

Source: Authors' own upon data of The Retail Data Partnership Ltd.

Consequently, we distinguish two periods in our investigation: pre-pandemic (Jan 2018 - Feb 2020) and pandemic period (March 2020 - Dec 2020). We analyse 783,501 transactional observations that needed to be ordered into panels (1291 convenience stores in the period of 36 months). In our research we use the dedicated software (Stata 15) and receive the balanced panels with 46476 observations (aggregated with respect to some aspects e.g. store affiliation, product category). Descriptive statistics of the analysed indicators/characteristics of the purchase habits and routines (percentage share of the number of single basket transactions in all recorded transactions, percentage share of the value of single basket transactions in the overall turnover, the average basket spend) supports the approach to divide the 36 month time into pre-pandemic and pandemic periods since they are meaningfully different (see Table 2).

Starting from the mean analysis in the pre-pandemic period it was much higher than in the pandemic one for both: share of single basket transactions in the number of all recorded transactions (by 5.53 percentage points) and share of the value of single basket transactions in the overall turnover (by 5.21 percentage points). In the case of the average basket spend the pre-pandemic mean was $£ 2.116$ lower than the pandemic one (Table 2). Similar tendency is noted in the context of percentiles analysis, supported also by minimum, maximum and standard deviation output. Skewness and kurtosis are also higher in the prepandemic than pandemic period in the case of share of single basket transactions in the number of all recorded transactions (difference equals 0.119 and 0.479 respectively) and share of the value of single basket transactions in the overall turnover (difference equals 0.327 and 2.377 respectively). Simultaneously skewness and kurtosis of the average basket spend are lower in the pre-pandemic than pandemic period (difference equals 0.617 and 8.854).

Following the descriptive statistics we run regression models on our unique panel dataset. Since the explanatory variables are binary we run random effects models (Cameron and Trivedi 2005). Moreover the Breusch and Pagan Lagrangian Multiplier Test for Random Effects (Breusch and Pagan 1980) is performed. 
Each time the null hypothesis (that there are no random effects between subjects) is rejected. This indicates the necessity to estimate the parameters of the random effects model.

Table 2

Descriptive statistics of three analysed indicators/characteristics of purchase habits and routines

\begin{tabular}{|c|c|c|c|c|}
\hline & & $\begin{array}{l}\text { Share of single basket } \\
\text { transactions in the } \\
\text { number of all } \\
\text { recorded transactions } \\
(\%)\end{array}$ & $\begin{array}{l}\text { Share of the value } \\
\text { of single basket } \\
\text { transactions in the } \\
\text { overall turnover } \\
(\%)\end{array}$ & $\begin{array}{c}\text { The average } \\
\text { basket spend } \\
(£)\end{array}$ \\
\hline \multirow{3}{*}{$\begin{array}{l}\text { Number of } \\
\text { observations }\end{array}$} & total period & 46476 & 46476 & 46476 \\
\hline & pre-pandemic & 33566 & 33566 & 33566 \\
\hline & pandemic & 12910 & 12910 & 12910 \\
\hline \multirow[b]{3}{*}{ Mean } & total period & 19.608 & 21.129 & 6.822 \\
\hline & pre-pandemic & 21.144 & 22.577 & 6.235 \\
\hline & pandemic & 15.614 & 17.365 & 8.351 \\
\hline \multirow[b]{3}{*}{$25^{\text {th }}$ percentile } & total period & 14.809 & 15.894 & 5.570 \\
\hline & pre-pandemic & 16.663 & 17.616 & 5.304 \\
\hline & pandemic & 11.374 & 12.585 & 7.150 \\
\hline \multirow[b]{3}{*}{$50^{\text {th }}$ percentile } & total period & 18.591 & 20.162 & 6.495 \\
\hline & pre-pandemic & 19.934 & 21.360 & 6.042 \\
\hline & pandemic & 14.403 & 16.237 & 8.113 \\
\hline \multirow[b]{3}{*}{$75^{\text {th }}$ percentile } & total period & 22.950 & 24.980 & 7.709 \\
\hline & pre-pandemic & 24.028 & 26.163 & 6.906 \\
\hline & pandemic & 18.331 & 20.719 & 9.180 \\
\hline \multirow[b]{3}{*}{ Min } & total period & 1.464 & 1.136 & 2.201 \\
\hline & pre-pandemic & 3.580 & 3.660 & 2.201 \\
\hline & pandemic & 1.464 & 1.136 & 3.008 \\
\hline \multirow[b]{3}{*}{ Max } & total period & 61.361 & 100.000 & 36.065 \\
\hline & pre-pandemic & 61.361 & 100.000 & 26.737 \\
\hline & pandemic & 57.484 & 79.150 & 36.065 \\
\hline \multirow[b]{3}{*}{ Standard deviation } & total period & 7.347 & 7.903 & 1.965 \\
\hline & pre-pandemic & 7.072 & 7.615 & 1.575 \\
\hline & pandemic & 6.496 & 7.378 & 2.053 \\
\hline \multirow[b]{3}{*}{ Skewness } & total period & 1.085 & 1.150 & 2.663 \\
\hline & pre-pandemic & 1.237 & 1.237 & 3.566 \\
\hline & pandemic & 1.356 & 1.564 & 2.949 \\
\hline \multirow[b]{3}{*}{ Kurtosis } & total period & 5.167 & 6.104 & 20.650 \\
\hline & pre-pandemic & 5.570 & 6.249 & 33.063 \\
\hline & pandemic & 6.049 & 8.626 & 24.209 \\
\hline
\end{tabular}

Source: Authors' own upon data of The Retail Data Partnership Ltd 
This decision is also supported by the analysis of the interclass correlation. In all estimated models rho (fraction of variance due to u_ii) coefficient equals more than $80 \%$. Additionally stationarity of the dependent variables is tested. We work on the balanced panels therefore the Harris-Tzavalis test is applied. The null hypothesis that the analysed data has a unit root is rejected. Thus the procedure confirmed that the dependent variables are stationary.

\section{EMPIRICAL RESULTS}

To reach our research aims we conduct detailed analysis letting us to test the formulated hypotheses. Therefore we run random effects models widening our understanding of correlations between our dependent variables and the whole variety of explanatory variables (time, location, affiliation, ONS regions and store size). All independent variables in our models are dummy variables. Reference time period starts in January 2018 and finishes in February 2020 (pre-pandemic), reference location is England, reference stores are affiliated, reference Office for National Statistics location is urban larger (following the ONS Rural/Urban Classifications (ONS 2021)) and reference store size is medium (average turnover in this store is more than 0.5 and less than 1.5 of average turnover for all analysed stores and the number of tills equals 1 or 2$)$.

The first random effects model is estimated for percentage share of single basket transactions in the number of all recorded transactions (the dependent variable). Table 3 presents our results. Our model shows that percentage share of single basket transactions in the number of all recorded transactions is consistently lower in the analysed pandemic period than in the pre-pandemic one, given the same levels of our control variables (location, affiliation, ONS region, store size). The highest drop is observed in April and May 2020 (coefficients equal -8.640 and -7.741 respectively). Then, from July till December 2020, the share of single basket transactions in the number of all recorded transactions stabilises at the level of around 5 percentage points lower than the mean coefficients in the analysed pre-pandemic period. All coefficients for time period as the independent variables are statistically significant at the $1 \%$ level.

In terms of ONS region (see Table 3) the only statistically significant results are obtained for Town and Fringe Villages and Remote Rural ONS regions. In both cases the average percentage share of single basket transactions in the number of all recorded transactions are smaller than in the Urban Larger ONS region, all other factors being equal. The smallest coefficient (-6.589) is noted for the Fringe Villages and Remote Rural ONS region.

Analysis of further independent variables being stores characteristics (see Table 3) shows that store size brings statistically significant results for all categories at the $1 \%$ level. In large stores the mean of percentage share of single basket transactions in the number of all recorded transactions is smaller than in medium stores and in small stores it is larger than in medium ones (coefficients equal -2.236 and 4.330 respectively). Additionally the first model (see Table 3) shows that the mean of percentage share of single basket transactions in the number of all recorded transactions in independent convenience stores is higher than in the affiliated ones (statistical significance at the 1\% level). Stores location analysis (see Table 3 ) does not bring statistically significant results for Scotland but in Northern Ireland the percentage share of single basket transactions in the number of all recorded transactions is meaningfully higher than in England (statistical significance at the 5\% level) and in Wales it is slightly lower than in England (statistical significance at the $10 \%$ level).

The value of $\mathrm{R}$-sq within equals 0.684 . It indicates that on average about $68.5 \%$ of the within-entity variation of the dependent variable is explained by the model over time, i.e. during 36 months under analysis. $\mathrm{R}$-sq between of 0.175 reveals that $17.5 \%$ of the between-entity variation in the dependent variable over time is captured by the model (i.e. our explanatory variables account for $17.7 \%$ of variation in the dependent 
variable between stores). The value of $\mathrm{R}$-sq overall equals 0.268 . It means that around $26.8 \%$ of the variation in the dependent variable is explained by the model. Rho (fraction of variance due to $\mathrm{u}_{-} \mathrm{i}$ ) coefficient equals 0.92 what can be interpreted that $92 \%$ of the variance in the dependent variable not explained by the model is due to variation in individual effects.

Table 3

Random effects model of percentage share of single basket transactions in the number of all recorded transactions as the dependent variable

\begin{tabular}{|l|c|c|}
\hline Independent Variable & Coefficient & $\mathbf{p}>|\mathbf{t}|$ \\
\hline March 2020 & -4.151 & $0.000^{* * *}$ \\
\hline April 2020 & -8.640 & $0.000^{* * *}$ \\
\hline May 2020 & -7.741 & $0.000^{* * *}$ \\
\hline June 2020 & -6.360 & $0.000^{* * *}$ \\
\hline July 2020 & -5.135 & $0.000^{* * *}$ \\
\hline August 2020 & -4.718 & $0.000^{* * *}$ \\
\hline September 2020 & -4.196 & $0.000^{* * *}$ \\
\hline October 2020 & -4.645 & $0.000^{* * *}$ \\
\hline November 2020 & -5.014 & $0.000^{* * *}$ \\
\hline December 2020 & -4.705 & $0.000^{* * *}$ \\
\hline Town and Fringe (ONS region) & -2.806 & $0.000^{* * *}$ \\
\hline Town and Fringe Sparse (ONS region) & 0.578 & 0.709 \\
\hline Urban Smaller (ONS region) & -0.370 & 0.611 \\
\hline Villages and Remote Rural (ONS region) & -6.589 & $0.000^{* * *}$ \\
\hline Large (store size) & -2.236 & $0.000^{* * *}$ \\
\hline Small (store size) & 4.330 & $0.000^{* * *}$ \\
\hline Unaffiliated (independent stores) & 2.991 & $0.000^{* * *}$ \\
\hline Scotland & 0.225 & 0.687 \\
\hline Wales & -0.787 & $0.065^{*}$ \\
\hline Northern Ireland & 4.681 & $0.019^{* *}$ \\
\hline constant & 21.495 & $0.000^{* * *}$ \\
\hline R-sq within & & 0.684 \\
\hline R-sq between & & 0.175 \\
\hline R-sq overall & & 0.268 \\
\hline Prob > chi2 & & 0.000 \\
\hline Rho (fraction of variance due to u_i) & & 0.920 \\
\hline Number of observations & & 46,476 \\
\hline Number of groups & & 1,291 \\
\hline Nots: Sto & & \\
\hline
\end{tabular}

Notes: *** Statistical significance at the $1 \%$ level.

** Statistical significance at the $5 \%$ level.

* Statistical significance at the $10 \%$ level.

Reference categories are: pre-pandemic period (January 2018-February 2020), urban larger (ONS region), medium (store size), affiliated stores, England.

Source: Authors' own upon data of The Retail Data Partnership Ltd.

The second random effects model is estimated for percentage share of value of single basket transactions in the overall turnover (the dependent variable). Our results are presented in Table 4. The second model (see Table 4) shows that percentage share of value of single basket transactions in the overall turnover is consistently lower in the analysed pandemic period than in the pre-pandemic one, all other 
factors being equal. The minimum percentage shares are observed in April and May 2020 (coefficients equal -8.391 and -7.609 respectively). In August 2020, the share of single basket transactions value in the overall turnover became relatively stable till December 2020 (at the level of around 4 percentage points lower mean than in the analysed pre-pandemic period, other things equal). All coefficients for time period as the independent variables are statistically significant at the $1 \%$ level.

Random effects model of percentage share of the value of single basket transactions in the overall turnover as the dependent variable

\begin{tabular}{|l|c|c|}
\hline Independent Variable & Coefficient & $\mathbf{p}>|\mathbf{t}|$ \\
\hline March 2020 & -4.105 & $0.000^{* * *}$ \\
\hline April 2020 & -8.391 & $0.000^{* * *}$ \\
\hline May 2020 & -7.609 & $0.000^{* * *}$ \\
\hline June 2020 & -6.250 & $0.000^{* * *}$ \\
\hline July 2020 & -5.034 & $0.000^{* * *}$ \\
\hline August 2020 & -4.405 & $0.000^{* * *}$ \\
\hline September 2020 & -3.531 & $0.000^{* * *}$ \\
\hline October 2020 & -3.931 & $0.000^{* * *}$ \\
\hline November 2020 & -4.384 & $0.000^{* * *}$ \\
\hline December 2020 & -4.482 & $0.000^{* * *}$ \\
\hline Town and Fringe (ONS region) & -4.337 & $0.000^{* * *}$ \\
\hline Town and Fringe Sparse (ONS region) & -1.202 & 0.382 \\
\hline Urban Smaller (ONS region) & -1.626 & $0.019^{* *}$ \\
\hline Villages and Remote Rural (ONS region) & -8.610 & $0.000^{* * *}$ \\
\hline Large (store size) & -1.784 & $0.000^{* * *}$ \\
\hline Small (store size) & 4.075 & $0.000^{* * *}$ \\
\hline Unaffiliated (independent stores) & 0.441 & $0.000^{* * *}$ \\
\hline Scotland & 1.070 & $0.092^{*}$ \\
\hline Wales & -0.103 & 0.830 \\
\hline Northern Ireland & 5.761 & $0.012^{* *}$ \\
\hline constant & 23.489 & $0.000^{* * *}$ \\
\hline R-sq within & & 0.509 \\
\hline R-sq between & & 0.189 \\
\hline R-sq overall & & 0.250 \\
\hline Prob > chi2 & & 0.000 \\
\hline Rho (fraction of variance due to u_i) & & 0.871 \\
\hline Number of observations & & 46,476 \\
\hline Number of groups & & 1,291 \\
\hline Nos: & & \\
\hline
\end{tabular}

Notes: *** Statistical significance at the $1 \%$ level.

** Statistical significance at the $5 \%$ level.

* Statistical significance at the $10 \%$ level.

Reference categories are: pre-pandemic period (January 2018-February 2020), urban larger (ONS region), medium (store size), affiliated stores, England.

Source: Authors' own upon data of The Retail Data Partnership Ltd.

In terms of ONS region the only coefficient that is not proven to be statistically significant is obtained for Town and Fringe Sparse (see Table 4). In all other ONS regions the percentage share of value of single 
basket transactions in the overall turnover is consistently lower than in urban larger (the minimum mean is observed for the Villages and Remote Rural ONS region (statistical significance at the 1\% level)).

Table 5

Random effects model of average basket spend as the dependent variable

\begin{tabular}{|c|c|c|}
\hline Independent Variable & Coefficient & $\mathrm{p}>|\mathrm{t}|$ \\
\hline March 2020 & 1.386 & $0.000^{* * *}$ \\
\hline April 2020 & 3.399 & $0.000^{* * *}$ \\
\hline May 2020 & 2.941 & $0.000^{* * *}$ \\
\hline June 2020 & 2.205 & $0.000^{* * *}$ \\
\hline July 2020 & 1.820 & $0.000^{* * *}$ \\
\hline August 2020 & 1.711 & $0.000^{* * *}$ \\
\hline September 2020 & 1.380 & $0.000^{* * *}$ \\
\hline October 2020 & 1.745 & $0.000^{* * *}$ \\
\hline November 2020 & 1.979 & $0.000^{* * *}$ \\
\hline December 2020 & 2.597 & $0.000^{* * *}$ \\
\hline Town and Fringe (ONS region) & 0.094 & 0.557 \\
\hline Town and Fringe Sparse (ONS region) & -0.394 & 0.223 \\
\hline Urban Smaller (ONS region) & -0.089 & 0.628 \\
\hline Villages and Remote Rural (ONS region) & 0.432 & $0.002^{* * *}$ \\
\hline Large (store size) & 0.443 & $0.005^{* * *}$ \\
\hline Small (store size) & -0.860 & $0.000^{* * *}$ \\
\hline Unaffiliated (independent stores) & 0.130 & 0.146 \\
\hline Scotland & 0.056 & 0.713 \\
\hline Wales & -0.124 & 0.217 \\
\hline Northern Ireland & -1.474 & $0.000^{* * *}$ \\
\hline constant & 6.161 & $0.000^{* * *}$ \\
\hline R-sq within & & 0.703 \\
\hline R-sq between & & 0.042 \\
\hline R-sq overall & & 0.287 \\
\hline Prob $>$ chi2 & & 0.000 \\
\hline Rho (fraction of variance due to $u \_i$ ) & & 0.841 \\
\hline Number of observations & & 46,476 \\
\hline Number of groups & & 1,291 \\
\hline
\end{tabular}

Notes: *** Statistical significance at the $1 \%$ level.

** Statistical significance at the $5 \%$ level.

* Statistical significance at the $10 \%$ level.

Reference categories are: pre-pandemic period (January 2018-February 2020), urban larger (ONS region), medium (store size), affiliated stores, England.

Source: Authors' own upon data of The Retail Data Partnership Ltd.

Analysis of control variables being stores characteristics (see Table 4) shows that also in that context store size brings statistically significant results for all categories at the $1 \%$ level. In large stores the mean of the percentage share of value of single basket transactions in the overall turnover is smaller than in medium stores and in small stores it is larger than in medium ones (coefficients equal -1.784 and 4.075 respectively), for the same level of other factors. Moreover the second model shows that the mean of the percentage share of value of single basket transactions in the overall turnover in independent convenience stores is higher than in the affiliated ones (statistical significance at the $1 \%$ level). Stores location analysis does not 
bring statistically significant results for Wales in this context but in Northern Ireland the percentage share of value of single basket transactions in the overall turnover is meaningfully higher than in England (statistical significance at the 5\% level). In Scotland this share is slightly higher than in England (statistical significance at the $10 \%$ level).

The value of $\mathrm{R}$-sq within equals 0.509 . It indicates that on average about $51 \%$ of the within-entity variation of the dependent variable is explained by the model over time, i.e. during 36 months under analysis. R-sq between of 0.189 indicates that approximately $19 \%$ of the between-entity variation in the dependent variable over time is captured by the model (i.e. our explanatory variables account for around $19 \%$ of variation in the dependent variable between stores). The value of $\mathrm{R}$-sq overall equals 0.25 . It means that $25 \%$ of the variation in the dependent variable is explained by the model. The rho (fraction of variance due to $\mathrm{u} \_$i) coefficient value of 0.871 reveals that around $87 \%$ of the variance in the dependent variable not explained by the model is due to variation in individual effects.

The third random effects model is estimated for average basket spend being the dependent variable. The third model (see Table 5) shows that the average basket spend is consistently higher in the analysed pandemic period than in the pre-pandemic one, given the same level of control variables. The highest coefficient is observed in April (3.399), then it gradually decreases till the level below two in July 2020 (coefficient equals 1.820) and, unsurprisingly, increases again at the end of the year (December coefficient equals 2.597). All coefficients for time period as the independent variables are statistically significant at the1\% level.

ONS regions analysis in that context (see Table 5) shows statistically significant result (at the $1 \%$ level) only for Villages and Remote Rural (coefficient equals 0.432 ). Further independent variables being stores characteristics demonstrate that store size brings statistically significant results for all categories at the $1 \%$ level. In large stores the average basket spend is higher than in medium stores and in small stores it is lower than in medium ones (coefficients equal 0.443 and -0.860 respectively), all other factors being equal. The third model (see Table 5) shows also that affiliation does not provide statistically significant results. The only store location bringing statistically significant result (at the 1\% level) is Northern Ireland and the average basket spend is lower here than in England (coefficient equals -1.474).

The value of $\mathrm{R}$-sq within equals 0.703 . It means that on average about $70 \%$ of the within-entity variation of the dependent variable is explained by the model. R-sq between of 0.042 reveals that approximately $4 \%$ of the between-entity variation in the dependent variable over time is captured by the model. The value of R-sq overall displays that around $29 \%$ of the variation in the dependent variable is explained by the model. Rho (fraction of variance due to $u_{-}$i) coefficient demonstrates that $84 \%$ of the variance in the dependent variable not explained by the model is due to variation in individual effects.

To conduct the robustness check some additional calculations were performed. In the models presented in Tables 3-5 all variables for which no statistical significance was found were eliminated (if one of the categories was not statistically significant, all categories of this variable were removed). Consequently we received models in which all explanatory variables were statistically significant. Both signs and values of coefficients of remaining independent variables (time period, store size and affiliation) did not change meaningfully. It confirms that our results are stable and robust.

\section{DISCUSSION AND CONCLUSIONS}

Our approach enabled us to reach the goal to contribute to the ongoing debate about various aspects of consumer purchase behaviour (e.g. Branco, Sun, and Villas-Boas, 2016; Davvetas and Diamantopoulos, 2017; Diallo, 2012; Orji, 2013; Prakash et al., 2019; Rybaczewska and Sułkowski, 2020) by contextualising it within the framework for understanding consumers' responses to threats (Campbell et al. 2020). 
Addressing this gap in knowledge and aiming to explore consumers' purchase habits and routines being among other aspects of consumer "adaptive" response to turbulent and unprecedented Covid-19 circumstances (lockdowns, regulations, restrictions etc.) we tested all formulated hypotheses.

Our findings let us conclude that consumers did not buy single items as often during Covid-19 pandemic as in the analysed pre-pandemic period (Jan 2018 - Feb 2020). The percentage share of single basket transactions in the number of all recorded transactions decreased in the analysed time of Covid-19 pandemic threat so the first hypothesis in this part (H1.1) is supported. Furthermore the highest drop in percentage share of single basket transactions in the number of all recorded transactions was noted when the first lockdown was fully introduced (April and May 2020). March 2020 was not that affected since the lockdown started in the middle of the month (on the 16th March). This observation is therefore contextualised within not only 'stay at home' and isolation governmental recommendations but also loneliness and other psychological consequences of Covid-19 pandemic threat (e.g. Miller 2020; Palgi et al. 2020; Zvolensky et al. 2020).

In terms of the ONS regions (connected with the isolation and loneliness issues (e.g. Brose et al. 2020; Monica and Ghayathri 2020)) our research reveals that these aspects more often play a meaningful role in the context of number and value of single basket transactions (see Table 3 and Table 4) than of average basket spend (see Table 5). It may be interpreted in the context of the personal interaction and relationships seeking (more connected with the number of visits in the store i.e. single basket transactions than with the average basket spend).

At the same time the location of convenience store does not belong to the independent variables providing results that are consistently statistically significant. Whilst cross-country and geographical analysis is very common research approach (e.g. Daniels, Wang, and Wong 2016; Islam et al. 2021; Van Auken, Barry, and Bagozzi 2006), our study shows that it is more meaningful in the context of single basket transactions than the average basket spend. We conclude also that it can be connected with the similarities of the Covid-19 governmental guidance and recommendations introduced in the area of the whole UK (especially in the most fundamental aspects).

Our study supports also the second part of the first hypothesis (H1.2) stating that percentage share of the value of single basket transactions in the overall turnover decreased in the analysed time of Covid-19 pandemic threat. Our observations referring to the change in time in that context are very similar to those connected with hypothesis H1.1. Therefore we can conclude that the value of single basket transactions and the number of such transactions are closely related (the items consumers bought separately were not exceptionally cheap/expensive). The shifts in purchase habits are observed therefore not only in terms of the number of single product transactions but also in their value.

The second hypothesis (H2) is also supported since the average basket spend did increase in the analysed time of Covid-19 pandemic threat. Our investigation shows that the break point is noted in April 2020 (similar to the single basket transactions context) which we link with the strict lockdown (introduced on the 16th March). Not surprisingly the average basket spend increased again towards December 2020. Such observations let us conclude that some purchase habits and routines changed temporarily but some followed long term seasonal trends (e.g. Roggeveen and Sethuraman 2020; Sheth 2020).

Moreover our research reveals that the convenience stores affiliation correlates with the share of single basket transactions in both the quantity and value of transactions (positive coefficients in both cases) but it is not proven to correlate with the average basket spend. We might therefore conclude that store affiliation in the convenience sector context can play more important role from the point of view of business functioning than from the consumers' perspective. This conclusion though would need further confirmation. 
Our findings let us address also the meaning of the convenience store size in the investigated context. Not unexpectedly, we claim that this store characteristics play an important role while analysing not only value and number of single basket transactions but also average basket spend. It is connected, among others, with the consumers' emotional perception of the ontological security and insecurity continuum.

Our research supports the claim that when consumers face a threat their purchase behaviour is different than in other times (e.g. Grashuis et al. 2020; Mandel and Smeesters 2008). Our findings contribute towards understanding the specific aspects of consumer "adaptive" response to threats i.e. purchase routines and habits (Campbell et al. 2020). They were meaningfully different during the Covid-19 pandemic which can be connected with the whole variety of determinants and drivers (e.g. Banham 2020; Mandel and Smeesters 2008; Rindfleisch et al. 2009). This reveals the power and meaning of the governmental recommendations and, additionally, shows specific inspirations for the future research in the field of consumers' reactions to various recommendations connected with threats including pandemic, climate catastrophes, economic crisis etc.

If the customers do not go to store to buy only one item do they buy more or just not come at all? Our research reveals that despite completely new and unexpected circumstances (work from home, social distance etc.) consumers did not resign from doing their shopping in the convenience stores, just the opposite. Instead of one item they put more in the basket and still used convenience stores with the personal interaction and all services they can provide.

Whilst our research is primarily about understanding the consumers' "adaptive" response to Covid-19 pandemic threat in the field of specific consumers' habits and routines indicators, its implications are far beyond the Covid-19 circumstances. We add to the debate on the influence of the Covid-19 pandemic disrupting various spheres of life (e.g. Bonaparte 2020; Leiva-Leon et al. 2020; Sułkowski 2020) and therefore ontological security of consumers. We address still underexplored Covid-19 threat consequences acknowledging its complexity and interdisciplinary character (e.g. Brose et al. 2020; Monica and Ghayathri 2020; Tahir and Batool 2020; Urch and George 2020).

We join also the discussion about consumers' behaviour when they face various threats which is priceless for the whole variety of reasons (Campbell et al. 2020). Firstly, it underpins the overall understanding of consumers' behaviour. Secondly, in-depth understanding of threat circumstances impacts on consumers enables making them more prepared for future threats by being more aware and therefore more proactive than reactive in the future (e.g. Banham 2020; Cannon et al. 2019; Ferraro et al. 2005). Thirdly, the business practitioners and policymakers can make such threat circumstances less harmful for the consumers. Finally, we emphasise the value and meaning of the convenience store sector not only generally but also, perhaps especially, in times of trouble. Our study supports also the claim that deep understanding of reactions to such unprecedented circumstances like Covid-19 pandemic plays an important role in the long-term process of knowledge building in the field of consumers' purchase behaviour (e.g. Campbell et al. 2020; Kirk and Rifkin 2020; Roggeveen and Sethuraman 2020; Sarkis 2021).

\section{LIMITATIONS AND FUTURE RESEARCH}

Among the limitations of our study we put the fact that while the data we analyse are fully credible they not fully represent every geographical region (especially Northern Ireland). Nevertheless we follow the claim of The Retail Data Partnership Ltd. that our dataset is representative for the UK as one country. We were not involved in the process of reaching the stores to receive the data but we realise some technical limitations and possible human mistakes (transactional data). We highly appreciate though the richness of the data and its consistency. 
Future research would be about exploring this richness in terms of further aspects of purchase behaviour e.g. particular products categories, particular brands. Additionally we plan to widen our investigation by expanding the timescale in our panel data. Such approach will reveal which shifts in consumers' purchase habits and routines observed in times of Covid-19 are permanent (Hesham et al. 2021; Sheth 2020). Cross-country analysis taking into account both different Covid-19 threat intensity/timing and various cultural and behavioural background/approach stays also as a task for the future.

\section{ACKNOWLEDGEMENTS}

We would like to thank The Retail Data Partnership Ltd. Their priceless contribution included, among others, providing us the access to the analysed dataset. Without their openness and willingness to assist this research would never be conducted and, consequently, this paper would never be written.

\section{REFERENCES}

A New Future for Scotland's Town Centres (2020), Town Centre Action Plan Review Group Report, https://www.gov.scot/publications/new-future-scotlands-town-centres/

ACS (2020), The Local Shop Report, Association of Convenience Stores https://www.acs.org.uk/research/localshop-report

ASC and SGF (2021), The Scottish Local Shop Report 2021, Association of Convenience Stores and the Scottish Grocers Federation, https://www.acs.org.uk/research/local-shop-report

Akhtar, Naeem, Muhammad Nadeem Akhtar, Muhammad Usman, Moazzam Ali, and Umar Iqbal Siddiqi (2020), Covid-19 Restrictions and Consumers' Psychological Reactance toward Offline Shopping Freedom Restoration, The Service Industries Journal, 40 (13-14), 891-913.

Atulkar, Sunil (2020), Brand Trust and Brand Loyalty in Mall Shoppers, Marketing Intelligence \& Planning, 38 (5), 559-72.

Banham, Rebecca (2020), Emotion, Vulnerability, Ontology: Operationalising 'Ontological Security'for Qualitative Environmental Sociology, Environmental Sociology, 6 (2), 132-42.

Bardhi, F. and G. M. Eckhardt (2017), Liquid Consumption, Journal of Consumer Research, 44 (3), 582-97.

Baumeister, Roy F, Cory J Clark, Jonghan Kim, and Stephan Lau (2017), Consumers (and Consumer Researchers) Need Conscious Thinking in Addition to Unconscious Processes: A Call for Integrative Models, a Commentary on Williams and Poehlman, Journal of Consumer Research. 44(2), 252-257.

Bonaparte, Yosef (2020), Pricing the Economic Risk of Coronavirus: A Delay in Consumption or a Recession?, Available at SSRN 3549597.

Bondi, Liz (2014), Feeling Insecure: A Personal Account in a Psychoanalytic Voice, Social \& Cultural Geography, 15 (3), $332-50$.

Branco, F., M. Sun, and J. M. Villas-Boas (2016), Too Much Information? Information Provision and Search Costs, Marketing Science, 35 (4), 605-18.

Breusch, Trevor S and Adrian R Pagan (1980), The Lagrange Multiplier Test and Its Applications to Model Specification in Econometrics, The review of economic studies, 47 (1), 239-53.

Brose, A., E. S. Blanke, F. Schmiedek, A. C. Kramer, A. Schmidt, and A. B. Neubauer (2020), Change in Mental Health Symptoms During the Covid-19 Pandemic: The Role of Appraisals and Daily Life Experiences, Journal of Personality, 89(3), 468-482

Cameron, A Colin and Pravin K Trivedi (2005), Microeconometrics: Metbods and Applications: Cambridge university press.

Campbell, M. C., J. J. Inman, A. Kirmani, and L. L. Price (2020), In Times of Trouble: A Framework for Understanding Consumers' Responses to Threats, Journal of Consumer Research, 47 (3), 311-26.

Cannon, Christopher, Kelly Goldsmith, and Caroline Roux (2019), A Self-Regulatory Model of Resource Scarcity, Journal of Consumer Psychology, 29 (1), 104-27. 
Daniels, J, M Wang, and MC Sunny Wong (2016), Individual Attitudes Towards the Impact of Multinational Corporations on Local Businesses: How Important Are Individual Characteristics and Country-Level Traits?, Applied Economics Letters, 23 (7), 526-31.

Davvetas, V. and A. Diamantopoulos (2017), Regretting Your Brand-Self? The Moderating Role of Consumer-Brand Identification on Consumer Responses to Purchase Regret, Journal of Business Research, 80, 218-27.

Diallo, Mbaye Fall (2012), Effects of Store Image and Store Brand Price-Image on Store Brand Purchase Intention: Application to an Emerging Market, Journal of Retailing and Consumer Services, 19 (3), 360-67.

Ferraro, Rosellina, Baba Shiv, and James R Bettman (2005), Let Us Eat and Drink, for Tomorrow We Shall Die: Effects of Mortality Salience and Self-Esteem on Self-Regulation in Consumer Choice, Journal of Consumer Research, 32 (1), 65-75.

Fetzer, Thiemo, Lukas Hensel, Johannes Hermle, and Christopher Roth (2020), Coronavirus Perceptions and Economic Anxiety, Review of Economics and Statistics, 1-36.

Giddens, Anthony (1991), Modernity and Self-Identity: Self and Society in the Late Modern Age: Stanford university press.

Grashuis, J., T. Skevas, and M. S. Segovia (2020), Grocery Shopping Preferences During the Covid-19 Pandemic, Sustainability, 12 (13), 10.

Hesham, Fazel, Harizi Riadh, and Nasr Khouadja Sihem (2021), What Have We Learned About the Effects of the Covid-19 Pandemic on Consumer Behavior?, Sustainability, 13 (8), 4304.

Islam, T., A. H. Pitafi, V. Arya, Y. Wang, N. Akhtar, S. Mubarik, and X. B. Liang (2021), Panic Buying in the Covid19 Pandemic: A Multi-Country Examination, Journal of Retailing and Consumer Services, 59, 13.

Keane, M. and T. Neal (2021), Consumer Panic in the Covid-19 Pandemic, Journal of Econometrics, 220 (1), 86-105.

Kirk, C. P. and L. S. Rifkin (2020), I'll Trade You Diamonds for Toilet Paper: Consumer Reacting, Coping and Adapting Behaviors in the Covid-19 Pandemic, Journal of Business Research, 117, 124-31.

Kłopocka, Aneta Maria (2017), Does Consumer Confidence Forecast Household Saving and Borrowing Behavior? Evidence for Poland, Social Indicators Research, 133 (2), 693-717.

Kotler, Philip and Gary Armstrong (2010), Principles of Marketing: Pearson education.

Laing, Robert (2010), The Divided Self: An Existential Study in Sanity and Madness: Penguin UK.

Lee, J. A. and J. J. Kacen (2008), Cultural Influences on Consumer Satisfaction with Impulse and Planned Purchase Decisions, Journal of Business Research, 61 (3), 265-72.

Leiva-Leon, Danilo, Gabriel Pérez-Quirós, and Eyno Rots (2020), Real-Time Weakness of the Global Economy: A First Assessment of the Coronavirus Crisis, https://papers.ssrn.com/sol3/papers.cfm?abstract_id=3617695.

Lien, Che-Hui, Miin-Jye Wen, Li-Ching Huang, and Kuo-Lung Wu (2015), Online Hotel Booking: The Effects of Brand Image, Price, Trust and Value on Purchase Intentions, Asia Pacific Management Review, 20 (4), 210-18.

Mandel, Naomi and Dirk Smeesters (2008), The Sweet Escape: Effects of Mortality Salience on Consumption Quantities for High-and Low-Self-Esteem Consumers, Journal of Consumer Research, 35 (2), 309-23.

Miller, E. D. (2020), Loneliness in the Era of Covid-19, Frontiers in Psychology, 11, 3.

Modliński, A., \& Gladden, M. (2021). Applying ethology to design human-oriented technology. Experimental study on the signalling role of the labelling effect in technology's empowerment. Human Technology, 17(2), 164-189. https://doi.org/10.14254/1795-6889.2021.17-2.5

Monica, B. S. and N. Ghayathri (2020), Impact of Work from Home on Employee Wellbeing During Pandemic, Journal of Contemporary Issues in Business and Government, 26 (2), 442-46.

Nicosia, Francesco M (1966), Consumer Decision Process, Prenntice Hall, Englewood Cliffs, New York.

Nurliza, N., \& Oktoriana, S. (2021). Perceived benefits of social media networks impact on competitive behavior of Indonesia SMEs: Food and beverage sector. Economics and Sociology, 14(3), 146-162. https://doi.org/10.14254/2071-789X.2021/14-3/8

ONS (2021), Internet sales as a percentage of total retail sales (\%), Office for National Statistics, https://www.ons.gov.uk/businessindustryandtrade/retailindustry/timeseries/j4mc/drsi

Orji, O Goodhope (2013), Major Classic Consumer Buying Behaviour Models: Implications for Marketing DecisionMaking, Journal of Economics and Sustainable Development, 4 (4), 164-73.

Ortega-Vivanco, M. (2020), Effects of Covid-19 on Consumer Behavior: Ecuador Case, Retos-Revista De Ciencias De La Administracion Y Economia, 10 (20), 233-47. 
Palgi, Y., A. Shrira, L. Ring, E. Bodner, S. Avidor, Y. Bergman, S. Cohen-Fridel, S. Keisari, and Y. Hoffman (2020), The Loneliness Pandemic: Loneliness and Other Concomitants of Depression, Anxiety and Their Comorbidity During the Covid-19 Outbreak, Journal of Affective Disorders, 275, 109-11.

Park, H. and Y.-K. Kim (2016), Proactive Versus Reactive Apparel Brands in Sustainability: Influences on Brand Loyalty, Journal of Retailing and Consumer Services, 29, 114-22.

Phipps, M. and J. L. Ozanne (2017), Routines Disrupted: Reestablishing Security through Practice Alignment, Journal of Consumer Research, 44 (2), 361-80.

Prakash, G., S. Choudhary, A. Kumar, J. A. Garza-Reyes, S. A. R. Khan, and T. K. Panda (2019), Do Altruistic and Egoistic Values Influence Consumers' Attitudes and Purchase Intentions Towards Eco-Friendly Packaged Products? An Empirical Investigation, Journal of Retailing and Consumer Services, 50, 163-69.

Prentice, C., J. Chen, and B. Stantic (2020), Timed Intervention in Covid-19 and Panic Buying, Journal of Retailing and Consumer Services, 57, 102203.

Rindfleisch, A., J. E. Burroughs, and N. Wong (2009), The Safety of Objects: Materialism, Existential Insecurity, and Brand Connection, Journal of Consumer Research, 36 (1), 1-16.

Roggeveen, A. L. and R. Sethuraman (2020), How the Covid-19 Pandemic May Change the World of Retailing, Journal of retailing, 96 (2), 169-71.

Rybaczewska, M. and L. Sparks (2019), Place Marketing and Place Based Loyalty Schemes, Journal of Enterprising Communities: People and Places in the Global Economy. 14(1), $42-56$.

Rybaczewska, M. and L. Sparks (2020), Locally-Owned Convenience Stores and the Local Economy, Journal of Retailing and Consumer Services, 52, 101939.

Rybaczewska, M., L. Sparks, and L. Sułkowski (2020), Consumers’ Purchase Decisions and Employer Image, Journal of Retailing and Consumer Services, 55, 102123.

Rybaczewska, M. and L. Sułkowski (2020), Company Image as an Employer on Poland's Mobile Telecommunication Market and Its Relationship with Consumer Recommendations, Entrepreneurial Business and Economics Review, 8 (2), 141-52.

Rybaczewska, M., Ł. Sułkowski, and Y. Bilan (2021), Covid-19 Pandemic and Independent Convenience Stores in the United Kingdom, Engineering Economics, 32 (3), 258-65.

Sarkis, J. (2021), Supply Chain Sustainability: Learning from the Covid-19 Pandemic, International Journal of Operations \& Production Management, 41 (1), 63-73.

Scheibehenne, B., R. Greifeneder, and P. M Todd (2010), Can There Ever Be Too Many Options? A Meta-Analytic Review of Choice Overload, Journal of Consumer Research, 37 (3), 409-25.

Shava, H. (2021). The relationship between service quality and customer satisfaction in the South African mobile network telecommunications industry. Journal of International Studies, 14(2), 70-83. doi:10.14254/2071$8330.2021 / 14-2 / 5$

Sheth, J. (2020), Impact of Covid-19 on Consumer Behavior: Will the Old Habits Return or Die?, Journal of Business Research, 117, 280-83.

Sułkowski, Łukasz (2020), Covid-19 Pandemic; Recession, Virtual Revolution Leading to De-Globalization?, Journal of Intercultural Management, 12 (1), 1-11.

Szymkowiak, A., P. Gaczek, K. Jeganathan, and P. Kulawik (2021), The Impact of Emotions on Shopping Behavior During Epidemic. What a Business Can Do to Protect Customers, Journal of Consumer Behaviour, 20 (1), 13.

Tahir, M. B. and A. Batool (2020), Covid-19: Healthy Environmental Impact for Public Safety and Menaces Oil Market, Science of the Total Environment, 740, 4.

Tvaronavičiené, M., Mazur, N., Mishchuk, H., \& Bilan, Y. (2021). Quality of life of the youth: assessment methodology development and empirical study in human capital management. Economic Research-Ekonomska Istraživanja, 1-18. DOI:10.1080/1331677X.2021.1956361

Urch, C. E. and A. J. T. George (2020), Covid-19: Less Haste, More Safety Let's Stop Talking About Covid-Safe and Covid-Secure-It's Covid-Mitigated, Bmj-British Medical Journal, 370, 1.

Van Auken, Stuart, Thomas E Barry, and Richard P Bagozzi (2006), A Cross-Country Construct Validation of Cognitive Age, Journal of the Academy of Marketing Science, 34 (3), 439-55. 
Williams, Lawrence E. and T. Andrew Poehlman (2017), Conceptualizing Consciousness in Consumer Research, Journal of Consumer Research, 44 (2), 231-51.

Wu, Yi, Liwei Xin, Dahui Li, Jie Yu, and Junpeng Guo (2021), How Does Scarcity Promotion Lead to Impulse Purchase in the Online Market? A Field Experiment, Information \& Management, 58 (1), 103283.

Zvolensky, M. J., L. Garey, A. H. Rogers, N. B. Schmidt, A. A. Vujanovic, E. A. Storch, J. D. Buckner, D. J. Paulus, C. Alfano, J. A. J. Smits, and C. O'Cleirigh (2020), Psychological, Addictive, and Health Behavior Implications of the Covid-19 Pandemic, Behaviour Research and Therapy, 134, 16. 